\title{
What Methodology Attributes Are Critical for Potential Users? Understanding the Effect of Human Needs
}

\author{
Kunal Mohan and Frederik Ahlemann \\ EBS Business School, Söhnleinstraße 8D, 65201 Wiesbaden \\ kunal.mohan@ebs.edu, frederik.ahlemann@ebs.edu
}

\begin{abstract}
Despite the overwhelming advantages of using IS development and management (ISDM) methodologies, organisations are rarely able to motivate their staff to use them. The resulting lack of methodology usage by individuals fails to deliver the expected advantages of better quality, control, less time, and less effort in IS development projects. We analyse the technical as well as non-technical aspects of an individual's use of ISDM methodologies, in order to enable organisations to engineer those that meet the needs of actual users and are actually used by them in a productive manner. We construct a conceptual model, based upon which, we posit that: technical methodology attributes such as relative advantage, complexity, compatibility, demonstrability, visibility, triability, and reinventability influence an individual's methodology usage behaviour. We also propose that the strengths of these relationships depend on non-technical, deeply rooted psychological needs of the people.
\end{abstract}

Keywords: Methodology acceptance, IS development, method engineering.

\section{Introduction}

In the search for ways to arrive at replicable, pragmatic, cost-effective, and timely solutions to real-world problems in systematic and predictable ways, organisations either adopt or customise and adaptively apply methodologies, which consist of tested bodies of methods, rules, and procedures. Despite the overwhelming advantages of using any methodology, only a handful of organisations are actually able to make their staff use such methodologies [18]. A software development project survey conducted by Russo et al. [41] shows that only $6 \%$ of organisations claim that their methodologies are always used as specified. Eva and Guilford [15] find that only 17\% of respondents, in their survey of 152 organisations, claim to use a methodology in its entirety. Organisational theorists have long recognised that individual behavioural resistance against new methodology use is because they might not share the goals of the organisations in which they work and that exert pressure on them to use new methodologies [46]. The roots of this problem of methodology acceptance, which our research addresses, lies - among other factors - in the failure to understand individual attitudes towards a methodology's use, which ultimately leads to the development and implementation of a methodology that might be considered unsuitable and might be rejected by users [31]. 
Diffusions of innovation theory (DOI) has directed considerable attention towards understanding the diffusion of innovations [38]. Research in a vast array of academic disciplines such as anthropology, communication, geography, sociology, marketing, political science, public health, economics, social psychology, sociology, and political science has applied DOI to understand the process through which new ideas and technologies become accepted by people. Some of these studies have attempted to examine individual usage behaviour regarding IS methodologies from a technology adoption perspective. They view software development methodologies as technology innovations and make use of DOI and the technology acceptance model (TAM) (e.g., $[22,37])$. Others apply sociological models such as the theory of planned behaviour (TPB) and Triandis's theory of interpersonal behaviour to examine the development of individuals' intention to use methodologies (e.g., [21,26]).

Both approaches come to similar conclusions, and state that methodology characteristic usefulness is the single most important determinant of methodology acceptance and use by its actual users [22,37]. Subsequent research has therefore focused on this particular variable, but has neglected other potential crucial methodology attributes. Critics have also suggested that TAM and TPB are too parsimonious and need to be expanded by integrating variables specific to the innovation under investigation [49]. However, even when a handful of researchers seek to examine other methodology attributes, attributes are found to be either not significant, or of negligible effect (e.g., $[22,37])$, partly because these studies neglect to integrate other non-technical and non-economic variables from related theoretical perspectives [49], such as personality attributes like needs of individuals. As Warner [53] observes, the concept of adoption is a complex social phenomenon that involves both technical and non-technical factors, and sociologists would undoubtedly agree with this view. Unfortunately, the various disciplines, generally concentrating on their individual variables, have neglected to incorporate personality attributes in understanding the methodology acceptance problem. Little is known about the interactive effects of the attributes of methodologies and the non-technical personality characteristics, and it seems reasonable that variables from both sets are important in explaining the problem at hand [53].

Our study seeks to identify additional methodology attributes and to examine which of these attributes is more important for which type of person in which situations. Neglecting the impact of such complex relationships might lead to results that are not always valid [23]. Our study is a step toward filling the gap in the methodology development, adoption and implementation literature, which until now has not developed a theoretically and practically complete and relevant taxonomy of potential methodology characteristics and has also not studied the effect of personal traits such as needs on the effectiveness of the various methodology attributes. This leads us to fundamental questions regarding the impact of methodology attributes on an individual's usage behaviour: a) Which methodology attributes affect an individual's decision to use it? b) How do basic individual needs influence the predictive power of these different methodology attributes?

The remainder of the paper is organised as follows: Section 2 defines the research scope, and provides an overview of the conceptual foundations and the basic theories that provide the framework for our conceptual model. We also discuss prior research on the topic in order to clarify what has been done and what needs to be done. In Section 3, we present our research model and hypotheses, pointing out validated 
survey instruments that might be used to operationalize our constructs. In Section 4 we discuss the study's implications and contributions. Being research-in-progress, in section 5, we outline the next steps in our research to describe how we plan to execute the study's next phase.

\section{Theoretical Foundations}

We focus on examining the behaviour of individual users rather than an organisation as a whole because, although a particular methodology is developed and implemented by an organisation, the extent of its use is usually decided by the methodology's actual users $[37,26]$. We also focus only on the use of methodologies instead of methods/techniques (e.g., stakeholder analysis, earned value analysis, etc.) and tools (e.g., CASE tools, Word/Excel templates, project management software, etc.), because tools, techniques, and methods can be used in the absence of a formal methodology, and the use of a methodology represents a radical change [22]. Reasons why new methodology adoption and use might be so different from and so much more challenging than the adoption of specific methods and tools lies partly in the tacit organisational and individual problems caused by the new methodology introduction. For example, the stress associated with the learning of a new methodology, fear, the impact on self-esteem and identity associated with the organisational restructuring or re-engineering as well as the emotional costs of role conflict and ambiguity and/or workplace transformation might be serious inhibitors of methodology acceptance and usage [51].

DOI has been used over the past five decades to study how innovations diffuse and become adopted within wider social networks [38]. While early research using DOI concentrated on the diffusion and acceptance of products, the research community recently reached consensus on the fact that ideas and practices such as methodologies can also be regarded as innovations if they are perceived to be new by the potential adopter [38]. The foundations of DOI can be traced back to the three mainstream school of thoughts of Bass [5], Moore [30], and Rogers [38], with the Rogers gaining more attention and popularity. Bass [5] used mathematical methods to develop a model of innovations diffusions in 1969 in which he proposed five adopter categories depicting which type of person adopt innovations, and when: innovators, early adopters, the early majority, the late majority, and laggards. Moore [30] developed his own model of technology diffusion using the same adopter categories and the same terms as Bass [5].

The major difference between the two schools was that Moore's [30] work was based on the assumption of a discontinuous innovation process and focused only on organization, with a new technology adoption requirement. However, the best-known innovation diffusion theory was introduced by Rogers in 1962 in Diffusion of Innovations. Rogers classifies diffusion in his innovation adoption framework into five stages: innovators, early adopters, the early majority, the late majority, and laggards, with $2.5 \%, 13.5 \%, 34 \%, 34 \%$, and $16 \%$ of the population respectively. According to Rogers, one of the most influential factors that determine an innovation's adoption rate is the innovation itself, i.e. its characteristics. Furthermore, differences between the adoption stages, i.e. how quickly an innovation gets adopted, depends on adopter 
characteristics such as socioeconomic status and personality values [53]. Another distinguishing feature of Rogers' theory, which makes it very attractive for our study, is that it can also be applied to individuals. As such, we find that Rogers' diffusion of innovations theory provides the most fertile theoretical foundation for our research.

A key aspect of diffusion theories relates to the perception of innovations by potential adopters. Based on DOI, a methodology's characteristics play a crucial role in how quickly it is accepted by potential users [9]. The more attractive the attributes of a methodology are perceived to be, the more swiftly it is accepted by potential users. Empirical studies related to Rogers' DOI theory have therefore focused on the identification and examination of innovations' characteristics. Rogers and Shoemaker's [40] comprehensive list includes relative advantage (e.g., profit, productivity, and the innovation's prestige-conferring qualities); compatibility with users skills and ways of working; complexity of use and understanding of the innovation; trialability (i.e. divisibility, as the ability to be tested by the potential adopter); and observability (the degree to which others see the results of use of an innovation; also called communicability) [53].

Extensive empirical research in the past has found that some of the elements are more important than others. After conducting a meta-analysis of 75 articles pertaining to innovation characteristics, Tornatzky and Klein [47] found that relative advantage, complexity, and compatibility were the only innovation characteristics consistently related to innovation adoption and implementation. Later, Moore and Benbasat [29] expanded Rogers and Shoemaker's [39] list to include image (enhancement of social image or status), result demonstrability (of tangible advantages), and voluntariness (free will to adopt). Although extensive empirical evidence in various fields suggests that these influences do hold [53] in the context of methodology adoption, except relative advantage, most of them have either been neglected or have been found to be insignificant. For example, in the study of Riemenschneider et al. [37], five theoretical models of individual intention to accept information technology tools were tested individually using least-square regression analysis, to understand why software developers accept or resist methodologies. They came to the following conclusions: perceived usefulness was the only significant variable across all five models ( $\mathrm{p}<$ 0.001 ), voluntariness was found not significant (or was not included) in three models, compatibility was found not significant (or was not included) in four models, and result demonstrability, complexity, observability, and image were found to be not significant (or were not included) across all five models. In their study, Hardgrave et al. [23] also study software developers' intentions to use methodologies, and also find usefulness to significant (although comparatively weaker), complexity to not be significant, and voluntariness and compatibility to be significant but weak.

Seeing the large gap in the innovation attributes proposed by DOI and those studied in the context of methodology acceptance, we identify two areas in need of attention: a) examining which of the wide number of innovation characteristics apply to the methodology domain, and b) which of these different attributes are more important to what type of individuals. While, as mentioned earlier, DOI does provide a comprehensive list of attributes to examine the former issue (a), the latter problem (b) is virgin territory.

Recently, consumer research has acknowledged that personality-specific traits are of greater interest than demographic or psychographic influences, since they are "at 
the heart of consumer attitude formation and behavioural intentions" [11]. Over the past few decades, various categories of needs theories - e.g., Maslow's well-known hierarchy of needs [28] - have been developed so as to understand and predict human behaviour. They have become widely accepted in research studies, because they are considered to be the most enduring ways to understand an individual's motivation to act in a particular way [3]. According to the needs theories, an individual in an agenttarget relationship is expected to be influenced by a certain user influence tactic (UIT), if this UIT corresponds to his or her desires and needs (e.g., the need for knowledge, affiliation with peers, etc.). Many definitions of basic needs have been proposed, of which Ryan and Deci's [42] is most consistent with the scope of this study. They indicate that "a basic need, whether it be a physiological need or a psychological need, is an energizing state that, if satisfied, conduces toward health and well-being but, if not satisfied, contributes to pathology and ill-being" [42]. This implies that, if an methodology attribute is not aligned with the potential adopters' basic needs, this might result in serious stress, anxiety, and depression, and that this discomfort might be visible in the weak effect of the particular attribute to motivate an individual to use the methodology. This view might help explain why previous methodology acceptance found inconsistent results (i.e. because they were void of personality factors such as needs of an individual).

Maslow's hierarchy of needs theory [27] is one of the most fundamental and influential needs theories. It suggests that there exists a hierarchy of needs and that certain lower needs must be satisfied in order for higher needs to be recognised as unfulfilled. However, critics of the theory state that: a) there is hardly any evidence of the existence of a definite hierarchy of needs or that fundamental human needs are nonhierarchical, and b) little evidence suggests that people satisfy only one motivating need at a time, except in situations where needs conflict (i.e. are mutually exclusive) [52]. Empirical research, finds that a) more than one need may motivate at any one time, and b) that different needs have different values for different people. For the purpose of our study, we therefore employ, Murray's theory of psychogenic needs [32], and Reiss' theory of 16 basic desires [36] as these are considered the most fundamental and comprehensive list of underlying psychological human needs and have been empirically tested in a number of studies.

\section{Conceptual Model and Research Hypotheses}

The decision as to whether or not to adopt a methodology often requires time, energy, and careful consideration by the potential adopter [38]. Based on the complementary use of DOI and needs theory in humanistic psychology, individuals are expected to use a methodology based on their perceptions that methodology attributes will enable them to fulfil their specific needs. Needs of an individual are therefore expected to play a moderating role (see Figure 1), and influence the explanatory power of the effect of different methodology attributes on an individual's use of a methodology. The reason why we focus on perceptions of methodology attributes, rather than primary attributes (intrinsic to a methodology, independent of the perceptions of potential adopters) is that individual behaviour is predicted by how one perceives these 
primary attributes [29]. Since different adopters might perceive primary attributes in different ways, their eventual behaviour might differ [29].

In our research, we specifically focus on moderating effects because, besides the examination of direct effects, scholars are increasingly seeking to understand complex relationships [23]. While the importance of taking moderation effects is emphasised repeatedly in the literature [10], its neglect has led to a lack of relevance, as "...relationships that hold true independently of context factors are often trivial" [23]. In the remainder of this section, we define each of the determinants, specify the role of key moderators, and provide theoretical justification for our hypotheses.

\subsection{Attributes of a Methodology}

Relative advantage (RA) is the degree to which a methodology is perceived as being superior to its precursor by potential adopters, which is either the previous way of doing things (if there is no current way), the current way of doing things, or doing nothing [9]. A methodology's superiority is not only measured in economic terms, but also in terms of reduced or increased status and other benefits (e.g., because of an increase in productivity and efficiency). The higher the relative advantage, the higher the rate of adoption, all other factors being equal. The expected favourable outcome or usefulness of a behaviour has emerged as a core construct in the field of MIS, driven largely by the use of the theory of planned behaviour (attitude) [1] and the technology acceptance model (TAM) (perceived usefulness) [12] in examining individual beliefs regarding performing a behaviour. A plethora of empirical research in various fields has confirmed that the favourable outcome or usefulness of a behaviour is the most important aspect in predicting it - e.g., [12,49,50]. Hardgrave et al. [22] state that "...usefulness generally has a beta (path coefficient) of around 0.60 in TAM studies". In the context of methodology adoption, Khalifa and Verner [26] find that better process and product quality have a substantial effect on a software developer's decision to use waterfall and prototyping methodologies. Riemenschneider et al. [37] apply five theoretical models and conclude that "... if a methodology is not regarded as useful by developers, its prospects of successful deployment may be seriously undermined". Consequently, we propose that relative advantage will have a positive effect of methodology use.

Complexity (CL) is the degree to which a methodology is perceived as difficult to understand and use. The more complex a methodology is perceived to be, the more resistance it is expected to generate. The complexity construct can be traced back to Bandura's [4] self-efficacy concept, which refers to the belief that one has the capability to perform certain actions in order to be able to use a methodology. Judgment of one's personal competence, reflected in one's self-efficacy, therefore not only determines if a person decides to use an methodology, but also how much effort he or she will expend to use it, how long he or she will persevere when confronting obstacles, and how resilient he or she will prove in the face of adverse situations [33]. The more complex a methodology is perceived to be, the more an individual doubts his or her own ability to be able to use a methodology properly. In technology adoption literature, complexity has been addressed through the ease of use construct (which is also based on the concept of self-efficacy), which refers to the degree to which a person believes that using a particular methodology would be a) free of physical and mental 
effort, and b) easy to learn [12]. Numerous empirical evaluations of self-efficacy and ease of use find them to be an important predictor of human behaviour (e.g., $[12,48-50])$ and therefore provide substantial justification for including the complexity construct in our model. As such, we propose that complexity will have a negative effect on methodology use.

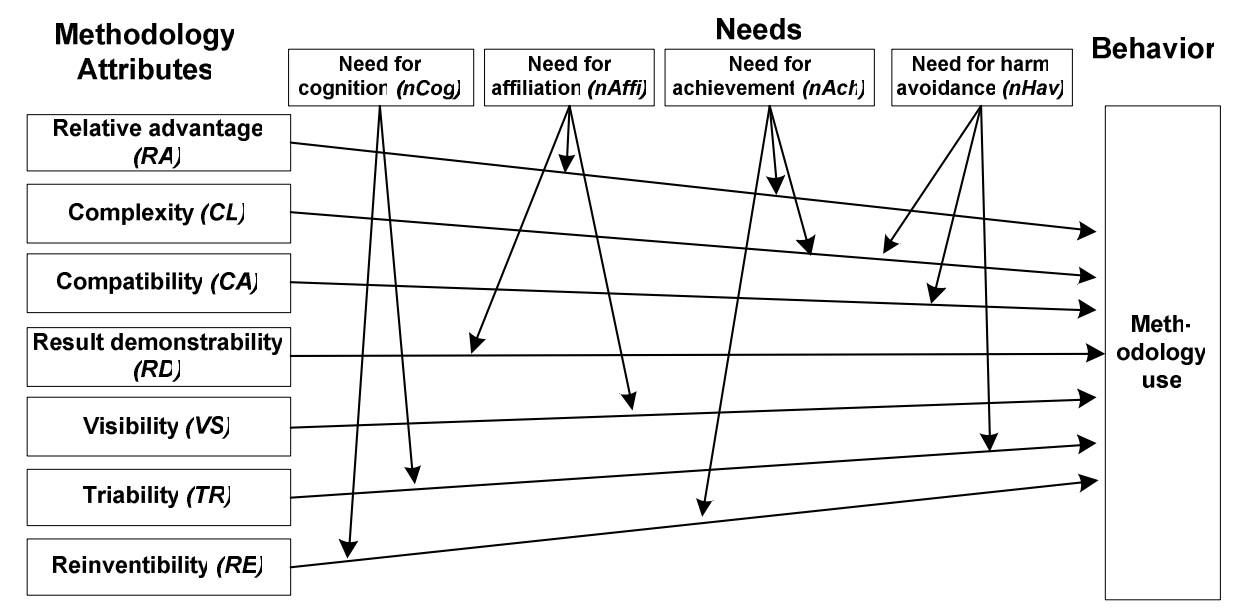

Fig. 1. Conceptual model

Compatibility $(C A)$ : is the degree to which a methodology is perceived to be consistent with existing social cultural values, and past experiences of potential adopters [9]. The higher the compatibility, the higher the desire to use the methodology. The roots of this lies in the understanding that individuals in organisations might be reluctant to change their habits, which they have learned unconsciously through past repetitions, and might therefore be unwilling to adopt new methodologies if they cause radical change. The more a methodology departs from the current work processes of an individual, the longer and harder he or she must strive to unlearn old routines and learn new ones [22]. In matters of radical change, as is the case with new methodology adoption (see Section 2), the methodology might not be compatible with the habits of potential users and would therefore activate negative feelings and emotions and, consequently, resistance. Past methodology acceptance research has found a significant positive but weak effect of compatibility on an individual's intention to use a methodology (e.g., [37]). However, research on this crucial construct is still relatively scarce, which calls for further attention. Based upon this discussion, we propose that compatibility will have a positive effect on methodology use.

Perceived observability is another attribute originally identified by Rogers [38]; it is the degree to which an individual believes that the results of using a methodology are visible [38]. However, this definition of observability indicates that the construct is complex and has been found to possess two unique dimensions [29]: a) the demonstrability of results to others, and b) the visibility of the innovation itself. While conducting a sorting exercise with a panel of judges, Moore and Benbasat [29] found 
that the items of the observability construct tapped into these two dimensions. As a result, they decided to split the construct into visibility and demonstrability. Similar to Moore and Benbasat [29], we hold that, in order to glean a deeper understanding of how observability influences methodology adoption, we need to study the effect of visibility and demonstrability individually. Result demonstrability (RD) is the degree to which the results of using a methodology are observable by others. While in some methodologies it is easy for others to see the results of a methodology's usage, this might not be the case with others (e.g., because of poor transparency or poor communication of outcomes achieved). Being able to show and communicate results achieved by using a methodology is important in acquiring tangible and intangible benefits such as praise, bonus, and promotion, since organisational incentive systems and management can only reward productive and efficient employees if they can observe these improvements. Furthermore, the easier it is for potential users to experience and see for themselves the positive effects of using a new methodology, the more confident they will be that they will also be able to realise the positive outcomes. In short, high observability acts as a motivator by reducing the risk in a potential adopter's mindset that using a methodology will be unfruitful (i.e. a high chance of the methodology not generating the promised positive results).

Result demonstrability might be especially critical to the methodology domain, because methodology outcome is characterised by the a) benefits not being realised swiftly [22], b) diffusion of potential benefits in a highly complex network of multiple actors. These characteristics make is hard to quantify and communicate total methodology usage benefits achieved to potential adopters (this is also a general problem in the IT field). Visibility (VS) is the degree to which a methodology is actually visible in the work environment. Visibility here implies that potential adopters can see their peers or seniors as they use methodologies, or know that they use them. Research has shown that mere exposure to objects (i.e. methodologies) is capable of rendering an individual's attitude towards these objects more positive. Extensive empirical research on human behaviour has shown that individuals would use a methodology because of their motivation to satisfy their notion of self-definition by doing what their peers (whom they want to be like) do [7]. Consequently, the more a potential adopter is able to observer his or her peers and seniors use a methodology, the more he or she will be inclined to use it. Consequently, we propose that result demonstrability and visibility will have a positive effect on methodology use.

Triability (TR) is the degree to which an individual believes he or she can experiment with a methodology on a limited basis prior to adoption. The chance to "test" a methodology prior to an individual making the final decision to adopt and use it helps to clear doubts relating to usefulness, complexity, and compatibility. High triability enables an individual to make a well-informed rational choice for himself, and is considered to be crucial for sceptical individuals who do not simply trust what they are told [16]. A number of studies also find strong evidence of the motivational effect of triability (e.g., [20,35]). Furthermore, prior testing of a methodology might also help a potential adopter to discover until then unknown or uncommunicated methodology benefits considered useful by the tester, since the evaluation of functionality is subjective and differs from person to person [16]. As such, we expect triability to have a positive effect on methodology use. 
Reinventability (RE) is the degree to which a methodology is perceived to be modifiable by a potential user. If potential adopters can adapt, refine, or otherwise modify the methodology to suit their own needs and situation, it will be adopted more easily [19]. The concept of reinvention - the assumption that one size does not fit all - has been embraced by researchers, to the extent that a dedicated research stream, entitled method engineering, has developed (e.g., [40]). A number of empirical studies find strong empirical evidence of the motivational effect of reinventability on a person's decision to use an innovation (e.g., [38]). Although this construct has been widely neglected in methodology acceptance studies, based upon existing research findings, we consider it an important predictor in our model. We propose that reinventibility will have a positive effect on methodology use.

Although Moore and Benbasat [29] propose voluntariness of use and image as further attributes, we hold that they might not apply to our research, since enhancement of social image can be considered an aspect of usefulness, rather than a distinct methodology characteristic. Rogers [38] also includes the concept of image under relative advantage. Furthermore, in our research, we consider methodology use to be voluntary. Even though organisations can deploy obligatory methodologies, their actual use in a productive manner cannot be forced, and correct usage is ultimately a voluntary user act.

\subsection{Personal Characteristics}

Need for affiliation (nAffi) is the desire to achieve acceptance from one's social surroundings [32]. Individuals with a high need for affiliation tend to enjoy being with other people, making friends, and maintaining personal relationships. In a work environment, materialistic status symbols like promotion, higher salary, gifts, and praise from seniors have been found in a number of studies to be conveyors of, and an adequate substitute for, positive interpersonal relationships and feelings of acceptance [6]. Also, since individuals high in $n A f f i$ depend on approval from their work environment, it is critical to them that the results are visible to their peers and superiors. Based on this reasoning, $n A f f i$ is expected to have a moderating effect on the strength of the effect of relative advantage $\rightarrow$ methodology use, result demonstrability $\rightarrow$ methodology use, and visibility $\rightarrow$ methodology use.

Need for achievement ( $n A c h$ ) refers to an individual's desire to do things better, accomplish difficult tasks, overcome obstacles and become an expert, achieve high performance standards, or a need for significant task-related accomplishment [32]. Such individuals are focused on internal motivation and personal achievement, rather than on external rewards and recognition. They would be more inclined to use a methodology if they feel that it is useful and would help them to be more efficient and productive in their job. Furthermore, the more complex a methodology, the more gratification/satisfaction people high in $n A c h$ are expected to feel, since being successful at using methodologies which others fail to master symbolises and communicates personal competence. Individuals high in $n A c h$ are expected to expend more effort and persevere longer when confronted with obstacles, and show resilience in the face of adverse situations [36]. In order to achieve high performance and excel at using a methodology, individuals high in $n A c h$ will be interested in modifying and 
adapting the methodology to suit their own skills set and context of use. We therefore propose that $n A c h$ will have a moderating effect on the strength of the effect of relative advantage $\rightarrow$ methodology use, complexity $\rightarrow$ methodology use, and reinventability $\rightarrow$ methodology use.

Need for cognition ( $\mathrm{nCog}$ ) is the desire for knowledge, reasoning $[32,36]$ as well as the need to explore and discover. Individuals high in $n \operatorname{Cog}$ tend to naturally seek, acquire, think about, and reflect on information by experimenting and exploring, to make sense of a problem at hand [8]. Therefore, people high in $n \operatorname{Cog}$ are more likely to want to try out methodologies, to better understand for themselves how proposed benefits are expected to be achieved, whether or not the promises are justified, and how their way of doing things changes. The desire to try out, extract, and process information by oneself, instead of simply "buying into" the anecdotes, demonstrations, reasoning tactics, and rational appeals of peers or experts is what characterises cognitive behaviour. Consequently, we expect $n \operatorname{Cog}$ to have a moderating effect on the strength of the effect of triability $\rightarrow$ methodology use, and reinventability $\rightarrow$ methodology use.

Need for harm avoidance ( $\mathrm{HHav}$ ) is a personality trait characterised by excessive worrying, pessimism, fearfulness, and doubtfulness. Harm-avoidant individuals are biased in the direction of seeking to end behaviours that might involve worrying, fear of uncertainty, and increased risk of anxiety [32]. As such, individuals high in $n H a v$ attempt to pursue behaviour that helps them reduce any risk and uncertainty attached to new methodology use. Methodologies that are considered complex and hard to execute are avoided, since risk of failure increases with rising complexity. A methodology perceived to be compatible with old routines involves minimal change and is therefore considered safe, because it corresponds to previous experience. Similarly, individuals will seek to experiment and try out methodologies prior to making their final choice, in order to identify those that might be potentially risky and carry a high degree of outcome uncertainty. As a result, we propose that $n H a v$ will have a moderating effect on the strength of the effect of complexity $\rightarrow$ methodology use, compatibility $\rightarrow$ methodology use, and triability $\rightarrow$ methodology use.

Empirical research has shown that the above-mentioned needs are largely uncorrelated with one another [36,45]. Although the list of needs in the literature is extensive, we consider these four needs to be representative of the most fundamental high-level primary needs in the context of influence tactics, in the sense of being innate or "hardwired" [45]. Other secondary needs can be derived from these high-level primary needs. For example, Murray's need for play, need for curiosity, and need for understanding may be attributed to $n C o g$, the need for contrarience, and the need for acquisition may be derived from $n$ Ach. The need for family - as proposed by Reiss [36] - and the need for social recognition may be attributed to nAffi, and the need to compete or win can also be derived from $n A c h$ [45]. Another reason to study fewer needs, rather than more, relates to the value of a parsimonious approach: as the list of needs increases, the utility of the approach diminishes. A long, unwieldy list of needs is precisely the reason why earlier needs-related theories fell out of favour [13].

The related research hypotheses are summarised in Table 1, which also provides an overview of some studies that have used validated instruments to operationalize the constructs of our conceptual model. 
Table 1. Research hypotheses and prior operationalization of constructs

\begin{tabular}{|c|}
\hline H1: RA $^{\mathrm{f}}$ is positively associated with methodology use ${ }^{\mathrm{a}}$ (MU). \\
\hline H2: $\mathrm{CL}^{\mathrm{g}}$ will be negatively associated with methodology use. \\
\hline H3: $\mathrm{CA}^{\mathrm{h}}$ will be positively associated with methodology use. \\
\hline H4: $\mathrm{RD}^{\mathrm{i}}$ will be positively associated with methodology use. \\
\hline H5: $\mathrm{VS}^{\mathrm{j}}$ will be positively associated with methodology use. \\
\hline H5: $\mathrm{TR}^{\mathrm{k}}$ will be positively associated with methodology use. \\
\hline H6: RE ${ }^{1}$ will be positively associated with methodology use. \\
\hline $\begin{array}{l}\text { H7: The influence of RA on methodology use will be moderated by } n A f f i^{\mathbf{b}} \text { and } n A c h^{\mathbf{e}} \text {, such that } \\
\text { the effect will be stronger for individuals with these specific needs. }\end{array}$ \\
\hline $\begin{array}{l}\text { H8: The influence of CL on methodology use will be moderated by } n A c h \text { and } n H a v^{\mathbf{c}} \text {, such that } \\
\text { the effect will be stronger for individuals with these specific needs. }\end{array}$ \\
\hline $\begin{array}{l}\text { H9: The influence of CA on methodology use will be moderated by } n H a v, \text { such that the effect } \\
\text { will be stronger for individuals with this specific need. }\end{array}$ \\
\hline $\begin{array}{l}\text { H10 The influence of RD on methodology use will be moderated by } n A f f i \text {, such that the effect } \\
\text { will be stronger for individuals with this specific need. }\end{array}$ \\
\hline $\begin{array}{l}\text { H11 The influence of VS on methodology use will be moderated by } n A f f i \text {, such that the effect } \\
\text { will be stronger for individuals with this specific need. }\end{array}$ \\
\hline $\begin{array}{l}\text { H12 The influence of TR on methodology use will be moderated by } n \operatorname{Cog}^{\mathrm{d}} \text { and } n H a v \text {, such that } \\
\text { the effect will be stronger for individuals with these specific needs. }\end{array}$ \\
\hline $\begin{array}{l}\text { H13 The influence of RE on methodology use will be moderated by } n \operatorname{Cog} \text { and } n A c h \text {, such that } \\
\text { the effect will be stronger for individuals with these specific needs. }\end{array}$ \\
\hline
\end{tabular}

\section{Discussion and Implications}

Our work seeks to further the research on acceptance and use of methodologies by individuals by unifying the theoretical perspectives on the attributes of a methodology and needs of individuals within a single model. Such a holistic approach for understanding why certain employees adopt a methodology while others reject it [25] is important, because people are not passive recipients of innovations. They actively seek new effective methodologies, “...experiment with them, evaluate them, find (or fail to find) meaning in them, develop feelings (positive or negative) about them, challenge them, worry about them, complain about them, 'work around' them, gain experience with them, modify them to fit particular tasks, and try to improve or redesign them-often through dialogue with other users" [19]. Only when we understand and acknowledge that such a diverse list of actions and feelings are typical of human behaviour, do we view the acceptance of new methodologies as a complex process and realise that research needs a holistic lens, integrating technical as well as nontechnical factors.

Based on validated theories, we develop a conceptual model that holds that personal traits of individual - especially their needs - determine which technical methodology attributes has a larger effect on an individual's use of a methodology. The proposed multidimensionality of "what is a methodology" from a technical perspective represents a departure from traditional operationalization (which is devoid of human factors) and might reveal more complex and as yet unknown interaction effects on human decision-making, especially in regard to the use of new methodologies. Our findings might have significant implications not only for the MIS research 
community, but also for related fields as it might be able to explain how changes in needs change attitudes and preferences. Human needs have always played a key role in organisational development, and the proposed study is an attempt to "humanise" organisational methodologies [2], that is, to enable organisations to be more responsive to human concerns when developing and implementing new methodologies. Furthermore, by creating a theoretically and practically relevant and parsimonious taxonomy of attributes of methodologies, we present researchers as well as practitioners with a framework to help identify and understand the characteristics that their methodologies possess or should possess.

Our research also has significant implications for practitioners. Each of the proposed constructs reveals a different aspect of human behaviour and personality, and each can serve as a point of attack for organisations in their attempts to steer them in the desired direction [1] by means of tailor-made methodologies. Our findings could help organisations manage the selection, development, and implementation of new methodologies. We would like to propose that future research study the determinants of the constructs identified in this study as well as the interrelationships between them. For example, we still know very little about how an organisation perceives the needs of their employees, since misinterpretation might lead to misleading conclusions. Another very promising focus area is how culture influences the importance assigned by individuals to the specific attributes. Although the understanding of cultural influences is repeatedly emphasised by top journal editors (e.g., Straub [43]), this is seldom incorporated in research generally, because of the difficulty of data collection. If it is successful in collecting data that is sufficient for statistical analysis from a wide range of different types of cultures (categorised by Hofstede [24]), our study - as proposed - will further improve the generalisability of our findings as well as seek to reveal new avenues for future research. A better understanding of these determinants would enable us to design organisational interventions that would increase new methodology usage in order to improve productivity and quality as well as to reduce effort.

\section{Future Research}

The next steps in our research include developing a survey instrument to test the presented conceptual model. Regarding the operationalization of the proposed constructs, there might be a possibility that prior instruments may not be suitable to establish appropriate levels of construct validity in the context of our study; new scales might therefore need to be developed. In developing the initial set of items, we will follow the advice of Straub [44] and employ a rigorous step-by-step iterative process as well as utilise the existing literature (see Table 2 for an overview of the prior operationalisation of constructs). After obtaining the initial battery of items, two researchers will conduct expert interviews with six subject matter experts (three academics and three practitioners) to obtain specific information as to whether the initial items are comprehensible, valid, and complete [44]. To further improve content and construct validity, we will then conduct a Q-sorting and item ranking in two rounds. In the final step, we will subject the questionnaire to a pre-test based on a convenience sample with individuals representing the target population. The final survey instrument will be 
administered web-based to a diverse population of methodology users, to collect quantitative data needed for testing the model and hypotheses. To understand cultural influences, data will be collected from the USA, Germany, Austria, Switzerland, and India. We will seek to include more countries, especially developing and Asian nations such as Japan, China, and the African nations, as research based on Hofstede's cultural dimensions [24] shows that individuals from these nations, when compared to Western nations, are governed by different attitudes, preferences, and norms.

In conclusion, user acceptance of organisational methodologies remains a complex and elusive yet extremely important phenomenon. Past research has made some progress in unravelling some of its mysteries. The development and testing of our model seeks to advance theory and research on this fundamental matter.

\section{References}

1. Ajzen, I.: The theory of planned behavior. Organizational Behavior and Human Decision Processes 50(2), 179-211 (1991)

2. Alderfer, C.P.: Organizational Development. Annual Review of Psychology 28, 197 (1977)

3. Arnolds, C.A., et al.: Does higher remuneration equal higher job performance?: an empirical assessment of the need-progression proposition in selected need theories. South African Journal of Business Management 31(2), 53 (2000)

4. Bandura, A.: Social foundations of thought and action: a social cognitive theory. Social Foundations of Thought and Action: A Social Cognitive Theory (1986)

5. Bass, F.M.: A New Product Growth for Model Consumer Durables. Management Science 15(5), 215-227 (1969)

6. Belk, R.W.: Materialism: Trait Aspects of Living in the Material World. Journal of Consumer Research 12(3), 265-280 (1985)

7. Burnkrant, R.E., et al.: Informational and Normative Social Influence on Buyer Behavior. Journal of Consumer Research 2(3), 206-215 (1975)

8. Cacioppo, J.T., et al.: Dispositional differences in cognitive motivation: The life and times of individuals varying in need for cognition. Psychological Bulletin 119, 197-253 (1996)

9. Chigona, W., et al.: Using Diffusion of Innovations Framework to Explain Communal Computing Facilities Adoption Among the Urban Poor. Information Technologies \& International Development 4(3), 57-73 (2008)

10. Chin, W.W., et al.: A Partial Least Squares Latent Variable Modeling Approach for Measuring Interaction Effects: Results from a Monte Carlo Simulation Study and an ElectronicMail Emotion/Adoption Study. Information Systems Research 14(2), 189-217 (2003)

11. Dabholkar, P.A., et al.: An Attitudinal Model of Technology-Based Self-Service: Moderating Effects of Consumer Traits and Situational Factors. Journal of the Academy of Marketing Science 30(3), 184-201 (2002)

12. Davis, F.D.: Perceived Usefulness, Perceived Ease of Use, and User Acceptance of Information Technology. MIS Quarterly 13(3), 319-340 (1989)

13. Deci, E.L.: The Darker and Brighter Sides of Human Existence: Basic Psychological Needs as a Unifying Concept. Psychological Inquiry 11(4), 319-338 (2000)

14. Edwards, A.L.: Edwards personal preference schedule. Psychological Corporation, New York (1959)

15. Eva, M., et al.: Committed to a Radical approach? A survey of systems development methods in practice. In: Proceedings of the Fourth Conference of the British Computer Society Information Systems Methodologies Specialist Group, pp. 87-96 (1996) 
16. Ford, G.T., et al.: Consumer Skepticism of Advertising Claims: Testing Hypotheses from Economics of Information. Journal of Consumer Research 16(4), 433-441 (1990)

17. Frs, R.H., et al.: A Validity Study of Scales to Measure Need Achievement, Need Affiliation, Impulsiveness, and Intellectuality. Educational and Psychological Measurement 32(1), 147-154 (1972)

18. Glass, R.L.: A Snapshot of Systems Development Practice. IEEE Softw. 16(3), 111-112 (1999)

19. Greenhalgh, T., et al.: Diffusion of Innovations in Service Organizations: Systematic Review and Recommendations. Milbank Quarterly 82(4), 581-629 (2004)

20. Grill, R., et al.: Evaluating the Message: The Relationship Between Compliance Rate and the Subject of a Practice Guideline (1992)

21. Hardgrave, B., et al.: Toward an information systems development acceptance model: the case of object-oriented systems development. IEEE Transactions on Engineering Management 50(3), 322-336 (2003)

22. Hardgrave, B.C., et al.: Investigating Determinants of Software Developers' Intentions to Follow Methodologies. Journal of Management Information Systems 20(1), 123-151 (2003)

23. Henseler, J., et al.: Testing Moderating Effects in PLS Path Models: An Illustration of Available Procedures. Handbook of Partial Least Squares, pp. 713-735 (2010)

24. Hofstede, D.G.: Culture's Consequences: Comparing Values, Behaviors, Institutions and Organizations Across Nations. Sage Publications, Inc., Newbury Park (2003)

25. Kanter, R.M.: Change Masters. Free Press, New York (1985)

26. Khalifa, M., et al.: Drivers for Software Development Method Usage. IEEE Transactions on Engineering Management 47(3), 360 (2000)

27. Maslow, A.H.: A Theory of Human Motivation. Psychological Review 50(4), 370-396 (1943)

28. Maslow, A.H.: Motivation and Personality. Harper \& Brothers (1954)

29. Moore, G., et al.: Development of an Instrument to Measure the Perceptions of Adopting an Information Technology Innovation. Information Systems Research 2, 3, 222, 192 (1991)

30. Moore, G.A.: Crossing the Chasm: Marketing and Selling High-Tech Products to Mainstream Customers. HarperBusiness (1999)

31. Munns, A., et al.: The role of project management in achieving project success. International Journal of Project Management 14(2), 81-87 (1996)

32. Murray, H.A.: Explorations in Personality. John Wiley \& Sons Inc., Chichester (1938)

33. Pajares, F.: Current directions in self-efficacy research. Advances in Motivation and Achievement 10, 1-49 (1997)

34. Pietrefesa, A.S., et al.: Moving Beyond an Exclusive Focus on Harm Avoidance in Obsessive Compulsive Disorder: Considering the Role of Incompleteness. Behavior Therapy 39(3), 224-231 (2008)

35. Plsek, P.E.: Complexity and the adoption of innovation in health care: For Accelerating Quality Improvement in Health Care Strategies to Speed the Diffusion of Evidence-Based. held in Washington, D.C. January 27-28, 2003. National Committee for Quality Health Care (2003)

36. Reiss, S.: Multifaceted Nature of Intrinsic Motivation: The Theory of 16 Basic Desires. Review of General Psychology 8(3), 179-193 (2004)

37. Riemenschneider, C.K., et al.: Explaining Software Developer Acceptance of Methodologies: A Comparison of Five Theoretical Models. IEEE Transactions on Software Engineering 28(12), 1135-1145 (2002)

38. Rogers, E.M.: Diffusion of Innovations, 5th edn. Free Press, New York (2003)

39. Rogers, E.M., et al.: Communication of Innovations: A Cross-Cultural Approach. Free Press, New York (1971) 
40. Rossi, M., et al.: Managing Evolutionary Method Engineering by Method Rationale. Journal of the Association for Information Systems 5(9), 356-391 (2004)

41. Russo, N.L., et al.: The Failure of Methodologies to Meet the Needs of Current Development Environments. In: Proceedings of the British Computer Society's Annual Conference on Information System Methodologies, pp. 387-393 (1996)

42. Ryan, R.M., et al.: Self-Determination Theory and the Facilitation of Intrinsic Motivation, Social Development, and Well-Being. American Psychologist 55(1), 68 (2000)

43. Straub, D.W.: Creating Blue Oceans of Thought Via Highly Citable Articles. MIS Quarterly 33(4), iii-vii (2009)

44. Straub, D.W.: Validating Instruments in MIS Research. MIS Quarterly 13(2), 147-169 (1989)

45. Sun, R.: Motivational Representations within a Computational Cognitive Architecture. Cognitive Computation 1(1), 91-103 (2009)

46. Teodoro, M.P.: Bureaucratic Job Mobility and The Diffusion of Innovations. American Journal of Political Science 53(1), 175-189 (2009)

47. Tornatzky, L.G., et al.: Innovation Characteristics and Innovation AdoptionImplementation: A Meta-Analysis of Findings. IEEE Transactions on Engineering Management 29, 28-45 (1982)

48. Venkatesh, V.: Determinants of Perceived Ease of Use: Integrating Control, Intrinsic Motivation, and Emotion into the Technology Acceptance Model. Information Systems Research 11(4), 342 (2000)

49. Venkatesh, V., et al.: A Theoretical Extension of the Technology Acceptance Model: Four Longitudinal Field Studies. Management Science 46(2), 186 (2000)

50. Venkatesh, V., et al.: User Acceptance of Information Technology: Toward a Unified View. MIS Quarterly 27(3), 425-478 (2003)

51. Vickers, M.H.: Information technology development methodologies. Journal of Management Development 18(3), 255 (1999)

52. Wahba, M.A., et al.: Maslow Reconsidered: A Review of Research on the Need Hierarchy Theory. Organizational Behavior \& Human Performance 15(2), 212-240 (1976)

53. Warner, K.E.: The Need for Some Innovative Concepts of Innovation: An Examination of Research on the Diffusion of Innovations. Policy Sciences 5(4), 433-451 (1974)

54. Wilson, R.S., et al.: Harm Avoidance and Disability in Old Age. Experimental Aging Research: An International Journal Devoted to the Scientific Study of the Aging Process 32(3), 243 (2006) 